\begin{tabular}{l|l|l|l}
$7^{\text {th }}$ CONGIC & Blucher Design Proceedings \\
$7^{\text {th }}$ Information Design & Setembro, 2015 - num. 2, vol.2 \\
proceedings.blucher.com.br
\end{tabular}

\title{
A percepção visual dos ladrilhos hidráulicos na cidade do recife e sua representação social por turistas brasileiros e devotos recifenses The visual perception of the hydraulic tiles in the city of Recife and its social representation by Brazilian tourists and devotees from Recife
}

\author{
Camila Brito de Vasconcelos, Silvio R. B. Barreto Campello
}

ladrilho hidráulico, representação social, núcleo central

\begin{abstract}
Este artigo expõe as abordagens sobre a representação social de Moscovici e o núcleo central de Abric. Apresenta a pesquisa de campo realizada e fim de testar esses conceitos aplicados ao artefato ladrilho hidráulico e seu contexto sendo percebido por perfis distintos. Trata principalmente da representação social do ladrilho hidráulico na cidade do Recife através de pesquisa de campo para identificação dos núcleos central e periférico das representações.
\end{abstract}

hydraulic tile, social representation, central core

This article discusses the approaches to social representation Moscovici and the central core of Abric. Displays conducted field research and to test these concepts applied to the hydraulic tile artifact and its context is perceived by different profiles. Deals primarily with the social representation of hydraulic tile in the city of Recife through field research to identify the central and peripheral roles of representations.

\section{Introdução}

A teoria das representações sociais foi fundada por Serge Moscovici em 1921. O termo deriva do conceito de "representação coletiva" de Émile Durkheim (1858-1917) e surgiu de estudos da psicanálise sobre a transformação do conhecimento.

As representações sociais podem ser entendidas como uma forma de conhecimento socialmente partilhado e elaborado, como um sistema que registra relação com o mundo e com os outros. Elas interferem nos processos, diversificando a difusão e a assimilação dos conhecimentos, os desenvolvimentos individual e coletivo, a definição de identidades pessoais e sociais, a expressão dos grupos e as transformações sociais.

O ladrilho hidráulico é um artefato que interage com seu observador através da significação da informação visual que representa e esta é construída com base no repertório de cada sujeito observador. Suas memórias coletivas/sociais dinamizam e transformam as representações visuais presentes neste artefato.

Que memórias ele evoca? Qual o significado de seus desenhos? Como representam determinado significado? Essas e outras questões podem ser respondidas pelas percepções 
visuais que diferentes perfis de sujeitos assumem ao observar este artefato. Através de suas experiências anteriores, seu repertório visual, seus conhecimentos a respeito do contexto em

que estão inseridos ou sobre o próprio artefato é que as representações sociais são identificadas no artefato, combinando memórias individuais e coletivas na percepção de significados.

Para Moscovici a representação social funciona com a participação da informação, atitude e capo de representação. A informação participa com a organização dos conceitos de um determinando grupo a respeito de um objeto social; a atitude através da orientação global em relação ao objeto da representação social; e o campo de representação como sendo a ideia de imagem, ao conteúdo concreto e limitado de proposições acerca de um aspecto preciso do objeto.

Esses participantes atuam nas funções essenciais das representações sociais. São essas: 1.Funções de saber, que podem ser entendidas pelo saber prático, de senso comum, necessária para a comunicação social; 2 . Funções identitárias, que definem a identidade e permitem a especificidade dos grupos; 3 . Funções de orientação, que guiam comportamentos e práticas definindo o lícito/tolerável/aceitável; e 4. Funções justificatórias, que permitem justificar a posteriori as tomadas de posição e comportamentos, condutas em uma situação ou em relação a seus participantes.

As representações sociais têm por caráter funcional elaborar comportamentos e comunicação entre os indivíduos no cotidiano e elaborar o novo, o estranho, o não familiar, dando-lhes sentido e inteligibilidade. Esse se assemelha à significação conferida por observadores de representações visuais aos artefatos de design, principalmente no que se refere a atribuir sentido, tornar familiar, significar.

Esta aproximação também pode ser observada no trabalho que é feito coletivamente, nas conversações ou nas comunicações cotidianas através de dois mecanismos básicos (não excludentes, não cronológicos, mundo criado e compartilhado coletivamente): a ancoragem e a objetivação.

A ancoragem é o processo que aproxima o "estranho e sem sentido" de alguma categoria já existente. E a objetivação é o mecanismo através do qual as representações assumem uma forma concreta (imagem ou objeto).

Influenciados por esses dois processos e pelas funções das representações sociais, alguns teóricos como JODELET, DOISE e ABRIC desdobram a teoria das representações sociais de Moscovici em três abordagens, as chamadas culturalista, societal e estrutural, respectivamente.

A abordagem culturalista de Jodelet (2001) propõe o estudo dos processos e dos produtos, através da articulação entre as dimensões sociais e culturais que regem as construções mentais coletivas. A abordagem societal de Doise (2001) propõe a articulação de explicações de ordem individual e societal em 4 níveis: processo intra-individuais, interindividuais e situacionais, de posicionamento e sistema de crenças.

A abordagem estrutural, de Abric (2000) propõe a teoria do núcleo central com determinação de significação e organização interna. Esta abordagem parte do princípio de que só há mudança na representação social se seus elementos centrais forem transformados e é baseada nessa teoria do núcleo central que a pesquisa de campo deste artigo sustenta a organização dos elementos encontrados nas evocações a partir do artefato ladrilho hidráulico.

\section{Teoria do núcleo central | Abric}

A teoria do núcleo central de Abric entende a representação social como um conjunto organizado de informações, opiniões, atitudes e crenças a respeito de um dado objeto. Sua premissa é que 
para conhecer a representação social sobre determinado objeto para determinando grupo é essencial apreender a sua organização e a hierarquia que seus elementos mantem entre si.

Através desse desdobramento da teoria das representações sociais é possível procurar elementos constituintes do núcleo central do artefato em estudo e organizar este conteúdo, de modo que faça sentido de acordo com o contexto de seus sujeitos.

Essa coordenação dos elementos constituintes da acepção dos artefatos busca atender a duas funções principais: a função geradora e a função organizadora. A primeira dá significação e a segunda determina a relação entre seus elementos constitutivos. Essas duas funções podem ser atendidas seguindo indicadores de hierarquia propostos por Abric: a frequência de um item e a ordem de importância do mesmo.

A frequência de um item pode ser verificada da quantidade de vezes que determinado item é evocado/citado pelos sujeitos, caracterizando-o assim com alto indicador de frequência pela constância com que foi atribuído a determinado artefato.

A ordem de importância de um item pode ser verificada pela valoração atribuída pelos sujeitos à estima de determinado item com relação a sua conformação com o artefato em estudo. Estes valores são atribuídos pelos próprios sujeitos atribuindo maior ou menor importância a tal item na representação do artefato.

Figura 1: Indicadores cruzados.

\begin{tabular}{|c|c|c|}
\hline \multirow{5}{*}{ 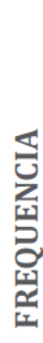 } & \multicolumn{2}{|c|}{ IMPORTÂNCIA } \\
\hline & 19 QUADRANTE & 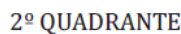 \\
\hline & $\begin{array}{l}\text { Núcleo } \\
\text { Central }\end{array}$ & $\begin{array}{l}\text { Primeira } \\
\text { Periferia }\end{array}$ \\
\hline & 3ํQUADRANTE & $4^{\circ}$ Q QUADRANTE \\
\hline & $\begin{array}{l}\text { Elementos de } \\
\text { contrastes }\end{array}$ & $\begin{array}{l}\text { Periferia } \\
\text { Distante }\end{array}$ \\
\hline
\end{tabular}

Esses indicadores são cruzados na tabela, acima representada, a fim de relacionar todos os itens de representação do artefato evocados pelos sujeitos para definição de seu núcleo central, elementos de contraste e periferias.

As vantagens do uso dessa teoria do núcleo central para identificação das representações sociais dos artefatos é que a mesma permite a atualização de elementos implícitos que poderiam ser diluídos ou mascarados em entrevistas convencionais. Por esse motivo é utilizada para a pesquisa de campo apresentada neste artigo a fim de testar sua contribuição para tal análise no artefato ladrilho hidráulico, bem como verificar a validade de uso para identificação de representações sociais neste artefato.

\section{Pesquisa de Campo}

Esta pesquisa de campo objetiva procurar elementos constituintes de seu núcleo central e organizar este conteúdo, de modo que faça sentido de acordo com o contexto de seus sujeitos, a fim de reconhecer as representações sociais sobre os ladrilhos hidráulicos da Basílica do Carmo 
no Recife para turistas brasileiros e devotos recifenses a partir das diferentes memórias identificadas. A partir dos elementos encontrados busca também identificar a validade da contribuição do uso da ferramenta.

Esta pesquisa foi estruturada para funcionar como um exercício de validação dessa ferramenta para este artefato e identificação de suas memórias e representações. $O$ universo estudado são os 19 bens materiais religiosos tombados pelo Instituto do Patrimônio Histórico e Artístico Nacional na cidade do Recife, registrados no livro de tombos Noronha Santos do arquivo central do IPHAN.

Neste universo de 19 bens tombados foi eleito para este exercício o que apresenta maior variedade de ladrilhos dentre todas as outras igrejas tombadas na cidade. O convento e igreja da ordem terceira de nossa senhora do Carmo do Recife, na Av. Dantas Barreto, apresenta maior variedade com 29 ladrilhos hidráulicos diferentes. Por este motivo, esta igreja é o local escolhido para a realização da pesquisa de campo.

Para a escolha dos ladrilhos que seriam utilizados, foi feita uma análise dos 29 ladrilhos da basílica do Carmo (anexo 2) a fim de identificar quais deles se repetem com mais frequência em outras igrejas tombadas na cidade. Após a análise, foram identificados 4 diferentes ladrilhos que também são encontrados em outras igrejas, dentre eles os listados na figura abaixo:

Figura 2: Ladrilhos mais frequentes nas igrejas tombadas.

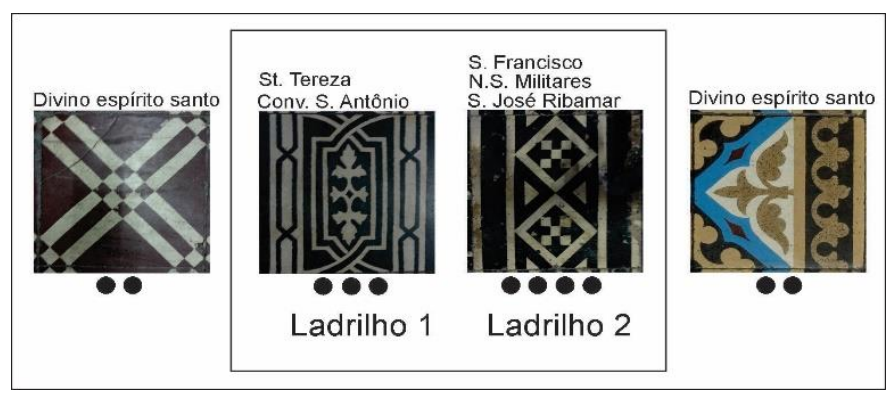

Dos quatro diferentes ladrilhos foram escolhidos os dois com maior frequência e representatividade: o ladrilho 1 foi encontrado em 3 igrejas, além da basílica a igreja de St ${ }^{a}$ Tereza e o convento de Sto Antônio; e o ladrilho 2 foi encontrado em 4 igrejas, além da basílica a igreja de S. Francisco, de № Sra $^{\text {a }}$ dos militares e a de S. José do Ribamar.

Quanto aos perfis de participantes, foi definido que seriam entrevistados dois perfis extremos para a obtenção de representações de contextos distintos testando assim a ferramenta do núcleo central também para essa identificação. Dessa forma os dois perfis participantes foram: os devotos recifenses, considerados os mais próximos possíveis do artefato e seu contexto; e turistas brasileiros, considerando o outro perfil extremo. Não foi considerado o perfil turista estrangeiro devido à divergência de contexto ainda maior não ser o foco desse estudo.

A quantidade de participantes foi definido com base no tempo disponível para a aplicação da pesquisa de campo bem como pela pretensão de teste da ferramenta aplicada a este artefato. Por isso participaram da pesquisa 6 sujeitos, sendo 3 de cada perfil apresentado anteriormente. Este número já possibilitou a soma de um número máximo de 60 evocações para a análise desta pesquisa, sendo 5 respostas para cada um dos 6 participantes sobre cada um dos 2 ladrilhos.

A pesquisa foi realizada no local e com ladrilhos indicados acima com os perfis e participantes citados, com a aplicação de um questionário (anexo 1). A abordagem ao participante foi feita apenas aqueles que se encontravam dentro da igreja e observando ou fotografando um dos ladrilhos pesquisados, para que não houvesse indução ao convidá-los a

Anais [Oral] do 7º Congresso Internacional de Design da Informação | CIDI 2015

Proceedings [Oral] of the 7th Information Design International Conference / IDIC 2015 
observar o artefato e facilitar a abordagem a sujeitos que tivessem o mínimo interesse ou curiosidade pelo artefato.

Após apresentação dos pesquisadores, foi solicitado ao participante que respondesse o questionário identificando-se como turista brasileiro ou devoto recifense. Após identificação foram apresentadas as imagens impressas $(5 \times 5 \mathrm{~cm})$ dos dois ladrilhos isolados que estavam sendo, ao mesmo tempo, observados em composição com seus módulos e em seu contexto original. Foi solicitado que 5 palavras fossem evocadas (representam elementos do universo simbólico do termo ou objeto)com a observação de cada um dos 2 ladrilhos (um por vez), bem como estabelecida uma ordem de 1 a 5, em função da importância de cada termo, para cada uma das 5 palavras evocadas.

Por fim, em uma terceira resposta, foi solicitada uma justificativa para a importância atribuída a evocação numerada com ordem de importância 1. Essa justificativa não foi utilizada diretamente nos resultados, mais serviu como base para o agrupamento das evocações em palavras chaves.

\section{Análise dos dados}

Para a análise dos dados foram rejeitados questionários de participantes que demonstraram pressa ou algum desconforto durante a pesquisa, considerando que esse fator poderia influenciar a representatividade das evocações. Por esse motivo mais sujeitos participaram da pesquisa e 6 questionários (número definido anteriormente), 3 de cada perfil, tiveram seus resultados analisados e tabulados, resultando nas 60 evocações abaixo com as respectivas ordens de importância atribuídas pelos participantes de 1 a 5:

Figura 3: Evocações. 


\begin{tabular}{|c|c|c|c|c|}
\hline \multicolumn{5}{|c|}{ EVOCAÇÕES } \\
\hline & Ord & Devoto Recifense & Ord & Turista Brasileiro \\
\hline & & & & \\
\hline \multirow{15}{*}{$\begin{array}{c}\text { Ladrilho } \\
1\end{array}$} & 2 & Tapete & 4 & Cromossomos \\
\hline & 5 & Parede de azulejo & 5 & Algas \\
\hline & 3 & Paisagem de quadros & 1 & Ruas \\
\hline & 4 & Jardim & 3 & Quadro pintado \\
\hline & 1 & Calçada & 2 & Mapa de localização \\
\hline & 2. & Calçada & 5 & Beleza \\
\hline & 5 & Mosaico & 4 & Diferente \\
\hline & 4 & Cruz & 1 & Flor \\
\hline & 1. & Flor do Carmelo & 3 & Quadro \\
\hline & 2 & União de fraternidade & 2 & Trilha \\
\hline & 3 & Bordado estola frades & 2 & Época Rei Arthur \\
\hline & 1. & Antiguidade & 3 & Santo grau \\
\hline & 3 & Folhagem & 1 & Cavaleiros Tábula \\
\hline & 4 & Natural & 4 & Alto Clero \\
\hline & 5 & Geométrica & 5 & Religiosidade \\
\hline \multirow{15}{*}{$\begin{array}{c}\text { Ladrilho } \\
2\end{array}$} & 5 & Azuleio & 2 & Medr \\
\hline & 4 & Rodapé & 5 & Abstrato \\
\hline & 3 & Canteiro de jardim & 4 & Flores \\
\hline & 1. & Divisão das plantas & 3 & Dinheiro \\
\hline & 2 & Calçada canteiro & 1 & Pressa \\
\hline & 3 & Bordado estola & 1 & Piso onde moro \\
\hline & 5 & Mosaico & 3 & Dado \\
\hline & 1 & Estrela & 4 & Triângulo \\
\hline & 2 & Passagem principal altar & 2 & Trilha \\
\hline & 4. & Estrela Maris & 5 & Quadrado \\
\hline & 5 & Geometria & 3 & Modernidade \\
\hline & 3 & Caminho & 1 & Atari \\
\hline & 2 & Calçada & 2 & Geometria \\
\hline & 4. & Padrão & 4 & Olhos de um sapo \\
\hline & 1 & Guia/Rota & 5 & Pessoa com boa triste \\
\hline
\end{tabular}

A primeira etapa das análises consistiu no agrupamento de evocações diferentes em palavras chaves comuns que representassem o mesmo conceito/ideia. Para que esta etapa não interferisse na qualidade dos resultados com possíveis erros de interpretação dos pesquisadores, foram analisadas as justificativas da questão 3 do questionário para identificação do sentido atribuído a cada evocação, agrupando-as assim em conceitos chaves.

O agrupamento foi realizado a partir da intersecção de respostas de cada perfil com cada ladrilho, resultando em 19 grupos de palavras evocadas como tabulado abaixo:

Figura 4: Palavras agrupadas.

\begin{tabular}{|c|c|c|c|c|}
\hline Total de palavras agrupadas: & \multicolumn{4}{|l|}{19 grupos } \\
\hline \multirow{4}{*}{$\begin{array}{l}\text { Geometria; Mosaico; } \\
\text { Natureza; Antiguidade; } \\
\text { Bordado; Religião; Quadro; } \\
\text { Calçada; Caminho/Rota; }\end{array}$} & Geometria & Calçada & Caminho/rota & Natureza \\
\hline & Mosaico & Caminho/Rota & História & Jogos \\
\hline & Natureza & Mosaico & Religião & Geometria \\
\hline & Antiguidade & Geometria & Ruas & Modernidade \\
\hline \multirow{5}{*}{$\begin{array}{c}\text { Construções; História; Ruas; } \\
\text { Belo/exótico; Jogos; } \\
\text { Modernidade; Piso/Moradia; } \\
\text { Dinheiro/pressa; Abstrato; } \\
\text { Medo. }\end{array}$} & Bordado & Natureza & Natureza & Piso moradia \\
\hline & Religião & Construções & Belo/exótico & Dinheiro/ pressa \\
\hline & Quadro & Bordado & Quadro & Abstrato \\
\hline & Calçada & Religião & & Medo \\
\hline & & & & Caminho/rota \\
\hline
\end{tabular}

Figura 5: Agrupamento das evocações de devotos recifenses. 

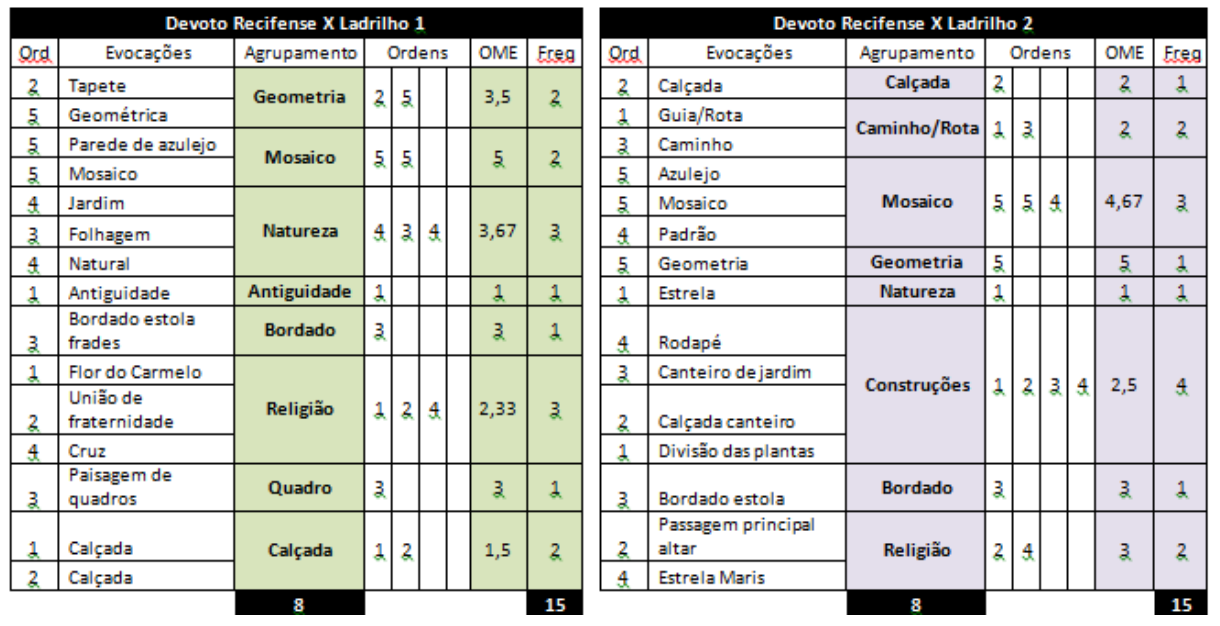

Figura 6: Agrupamento das evocações de turistas brasileiros.

\begin{tabular}{|c|c|c|c|c|c|c|c|}
\hline$Q_{d}$ & Evocações & Agrupamento & \multicolumn{3}{|c|}{ Ordens } & $\mathrm{OM}$ & Fre \\
\hline 2. & $\begin{array}{l}\text { Mapa de } \\
\text { localização }\end{array}$ & \multirow{2}{*}{$\begin{array}{c}\text { Caminho/rot } \\
\text { a }\end{array}$} & \multirow[t]{2}{*}{2} & \multirow{2}{*}{\multicolumn{2}{|c|}{2}} & \multirow[t]{2}{*}{2} & \multirow[t]{2}{*}{2} \\
\hline 2 & Trilha & & & & & & \\
\hline 2 & Época rei artbur & \multirow[b]{2}{*}{ História } & \multirow[b]{2}{*}{2} & \multirow{2}{*}{\multicolumn{2}{|c|}{1}} & \multirow[b]{2}{*}{1,5} & \\
\hline 1 & $\begin{array}{l}\text { Cavaleiros da } \\
\text { tábula }\end{array}$ & & & & & & 2 \\
\hline 3 & Santo grau & \multirow{3}{*}{ Religião } & \multirow{3}{*}{ z } & \multirow{3}{*}{\multicolumn{2}{|c|}{45}} & \multirow{3}{*}{4} & \multirow{3}{*}{3} \\
\hline 4 & Alto clero & & & & & & \\
\hline 5 & Religioso & & & & & & \\
\hline 1 & Ruas & Ruas & 1 & & & 1 & 1 \\
\hline 5 & Algas & \multirow{3}{*}{ Natureza } & \multirow{3}{*}{5} & \multirow{3}{*}{\multicolumn{2}{|c|}{124}} & \multirow{3}{*}{3,33} & \multirow{3}{*}{3} \\
\hline 1 & Flor & & & & & & \\
\hline 4 & Cromossomos & & & & & & \\
\hline 5 & Beleza & \multirow{2}{*}{ Belo/exótico } & \multirow{2}{*}{5} & \multirow{2}{*}{\multicolumn{2}{|c|}{4}} & \multirow{2}{*}{4,5} & \\
\hline 4 & Diferente & & & & & & \\
\hline 3 & Quadro pintado & \multirow{2}{*}{ Quadro } & \multirow{2}{*}{ z } & \multirow{2}{*}{\multicolumn{2}{|c|}{3}} & \multirow{2}{*}{3} & 2 \\
\hline 3 & Quadro & & & & & & \\
\hline
\end{tabular}

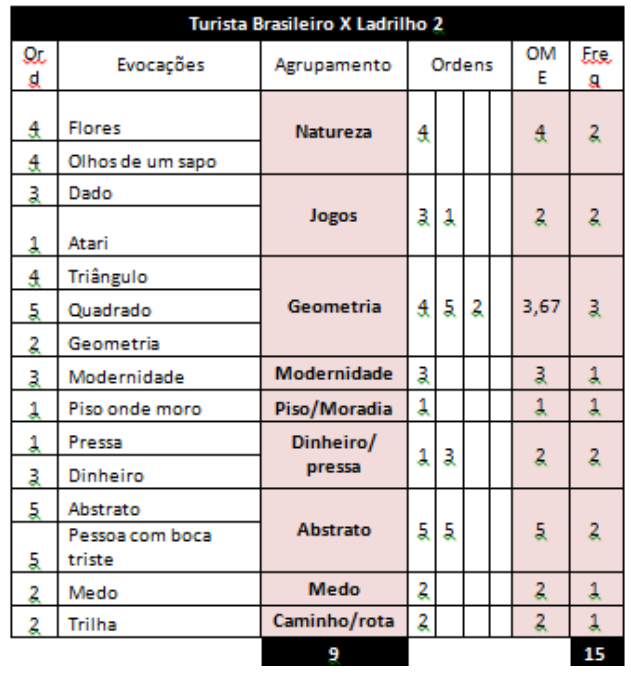

Após o agrupamento, os dados foram tratados como propõe a teoria do núcleo central de Abric (2000), já apresentada neste ensaio. Assim como sua teoria sugere, as informações foram cruzadas com distribuição do conteúdo coletado e analisado em 4 quadrantes para a identificação do núcleo central das representações, dos elementos de contraste e das periferias.

Figura 7: Tratamento dos dados. 


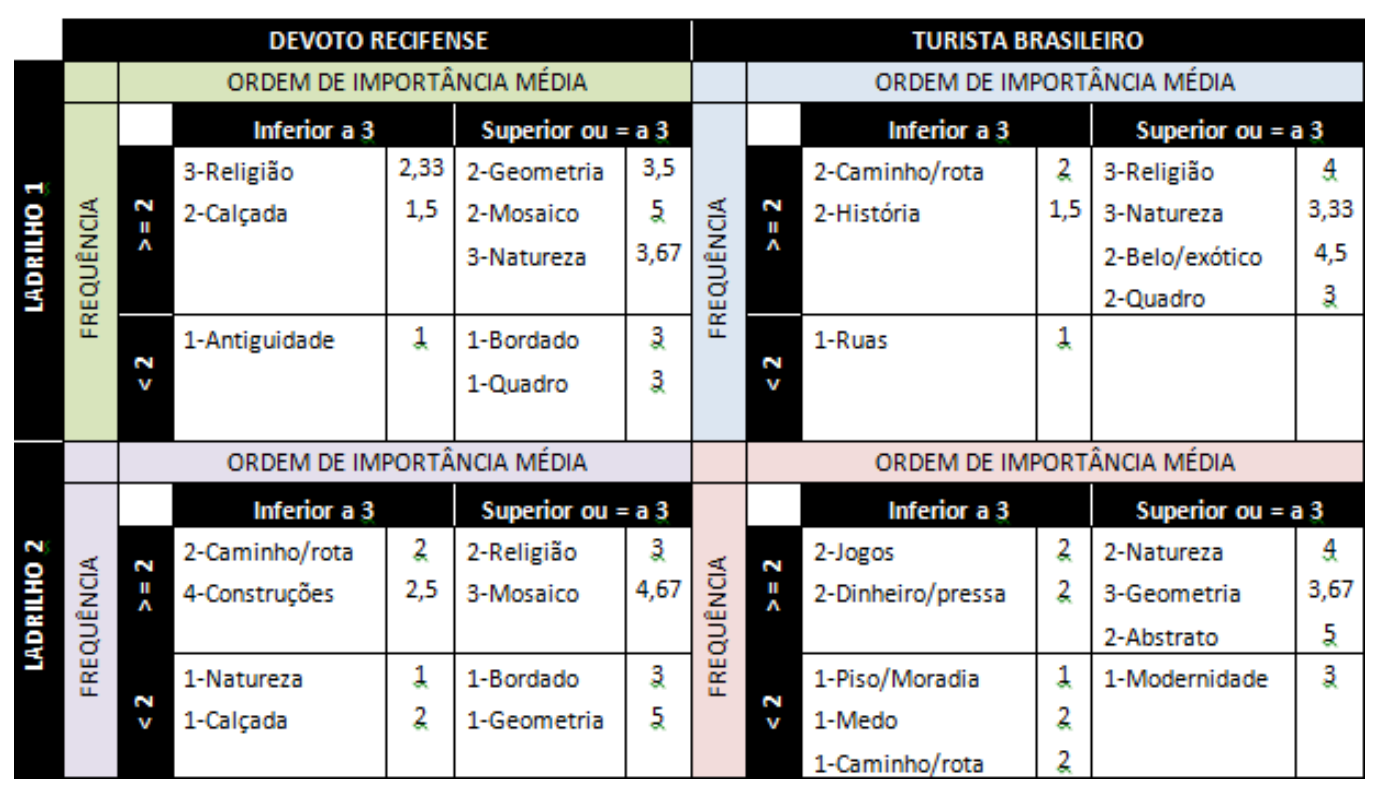

Os pontos de corte entre esses quadrantes foram definidos sob dois aspectos: a frequência das evocações e a ordem de importância atribuída.

Quanto à ordem média de evocação (ordem de importância média): Considerando 5 evocações o número máximo de evocações por participante e ladrilho, a média é 3 . Por isso a ordem média de evocação classificará as evocações entre o núcleo central e os elementos de contraste (inferior a 3) e a primeira periferia e a periferia distante (superior ou =a 3).

Quanto à Frequência (para as análises cruzadas dos diferentes perfis e ladrilhos): Considerando 4 o número máximo de repetições obtidas por grupo de palavras nas análises separadas por perfis e ladrilhos, o ponto de corte é 2 . Por isso a frequência média classificará as evocações entre o núcleo central e a primeira periferia (maior ou = a 2) e os elementos de contraste e a periferia distante (menor que 2).

\section{Núcleo Central}

Com os dados tabulados é possível apreender que na observação do ladrilho 1 os devotos recifenses participantes evocaram mais vezes palavras relacionadas a religião e calçada e estabeleceram maior ordem de importância a esses. Sendo assim considerados o núcleo central da relação devoto recifense $x$ ladrilho 1.

Na observação do ladrilho 2 esse mesmo perfil evocou mais vezes e estabeleceu maior importância a palavras relacionadas a construções e caminho/rota, sendo este o núcleo central desta relação devoto recifenses x ladrilho 2 .

Analisando o perfil de turistas brasileiros, suas percepções do ladrilho 1 estão mais voltadas para termos relacionados a história e caminho/rota, uma vez que foram as palavras mais evocadas e apontadas com maior nível de importância. Sendo este o núcleo central da relação turista brasileiro x ladrilho 1.

Ainda sobre a percepção dos turistas brasileiros, observando o ladrilho 2 evocaram mais palavras relacionadas a jogos e dinheiro/pressa, estabelecendo também maior ordem de importância a estas que caracterizam o núcleo central da relação turista brasileiro x ladrilho 2.

\section{Elementos de Contraste}

Anais [Oral] do 7º Congresso Internacional de Design da Informação | CIDI 2015

Proceedings [Oral] of the 7th Information Design International Conference / IDIC 2015 
Os elementos de contraste em cada intersecção entre perfis e ladrilhos nesta análise representam os termos que menos participantes evocaram, porém que tiveram ordem de importância atribuída alta pelos participantes que as citaram.

Na relação devoto recifense $x$ ladrilho 1 o elemento de contraste foi antiguidade, citado apenas uma vez mas considerado a representação mais importante para o participante que a evocou.

Na observação do ladrilho 2 esse mesmo perfil evocou menos vezes estabelecendo, porém, maior importância a palavras relacionadas a natureza e calçada, sendo estes os elementos de contraste desta relação devoto recifenses x ladrilho 2 .

Considerando o perfil de turistas brasileiros, sua percepção do ladrilho 1 está voltada, com menor frequência, para termos relacionados a ruas, uma vez que foi citado por apenas um participante mas com maior nível de importância. Sendo este o elemento de contraste da relação turista brasileiro x ladrilho 1 .

Observando o ladrilho 2 os turistas brasileiros evocaram menos palavras relacionadas a piso/moradia, medo e caminho rota, estabelecendo maior ordem de importância a estas que caracterizam os elementos de contraste da relação turista brasileiro x ladrilho 2.

\section{Primeira periferia}

A primeira periferia representa nesta análise os termos bastante citados, porém que tiveram ordem de importância atribuída baixa pelos participantes que as evocaram.

$\mathrm{Na}$ relação devoto recifense $\mathrm{x}$ ladrilho 1 a primeira periferia é representada por palavras relacionadas à geometria, mosaicos e natureza, citadas 7 vezes ao todo porém consideradas menos importantes pelos participantes que as evocaram.

Na observação do ladrilho 2 esse mesmo perfil evocou 5 vezes palavras relacionadas a religião e mosaico estabelecendo menor importância a estas, sendo esta a primeira periferia desta relação devoto recifenses x ladrilho 2 .

O perfil de turistas brasileiros, percebem o ladrilho $1 \mathrm{com}$ bastante frequência a termos relacionados a religião, natureza, quadro e belo/exótico, uma vez que palavras relacionadas foram citadas 10 vezes porém com baixo nível de importância. Sendo esta a primeira periferia da relação turista brasileiro x ladrilho 1 .

Já na observação do ladrilho 2 os turistas brasileiros evocaram 7 palavras relacionadas a geometria, natureza e abstrato, estabelecendo menor ordem de importância a estas que caracterizam a primeira periferia da relação turista brasileiro x ladrilho 2 .

\section{Periferia Distante}

A periferia distante em cada intersecção entre perfis e ladrilhos nesta análise representam os termos que menos participantes evocaram, e que tiveram ordem de importância atribuída baixa pelos participantes que as citaram. Por isso, os termos localizados nesta periferia são considerados de pouca representatividade para o artefato em estudo.

Na relação devoto recifense $x$ ladrilho 1, bordado e quadro foram citados apenas uma vez cada e considerados pouco importante para os participantes que as evocaram, fazendo parte portanto da periferia distante desta relação.

Na observação do ladrilho 2 esse mesmo perfil considerou pouco importante e apresentou apenas duas evocações relacionadas a bordado e geometria, sendo esta a periferia distante da relação devoto recifenses $x$ ladrilho 2 .

Quanto ao perfil de turistas brasileiros e sua percepção do ladrilho 1 nenhuma palavra foi citado poucas vezes e considerada com baixa ordem de importância. Sendo assim, a relação

Anais [Oral] do 7º Congresso Internacional de Design da Informação | CIDI 2015

Proceedings [Oral] of the 7th Information Design International Conference / IDIC 2015 
turista brasileiro x ladrilho 1 não apresenta periferia distante.

O ladrilho 2 observado pelos turistas brasileiros obteve apenas uma evocação da palavra modernidade, estabelecendo também pouca importância a esta, caracterizando a periferia distante da relação turista brasileiro x ladrilho 2.

\section{Resultados}

As análises feitas acima são consideradas especulativas, visto a pouca quantidade de participantes nesta pesquisa de campo, mas suficientes para atingir o objetivo de validar o uso da ferramenta para análise das representações sociais neste artefato. Pois foi possível estabelecer blocos de significação em cada quadrante identificando as tendências de cada perfil para cada ladrilho.

Portanto essa ferramenta é considerada valida para uso em futura pesquisa mais aprofundada sobre as representações sociais dos ladrilhos hidráulicos por diferentes perfis de observadores do artefato.

Embora os dados coletados com poucos participantes apresentem a análise como exercício, são apresentados nesta etapa resultados gerais com os dados tabulados direcionados para cada perfil e cada ladrilho sem interseções, unindo todas as evocações relacionadas a cada um destes. Estes resultados apresentaram maior consistência já que consideram todas as evocações juntas para cada tipo analisado.

Para estes resultados a frequência (para as compilações dos resultados gerais de cada perfil e ladrilho) considera 6 o número máximo obtido de repetições por grupo de palavras na compilação dos resultados dos perfis e ladrilhos, o ponto de corte é 3 . Por isso a frequência média classificará as evocações entre o núcleo central e a primeira periferia (maior ou $=a$ 3) e os elementos de contraste e a periferia distante (menor que 3 ).

\section{Ladrilho 1}

Figura 8: Ladrilho 1.

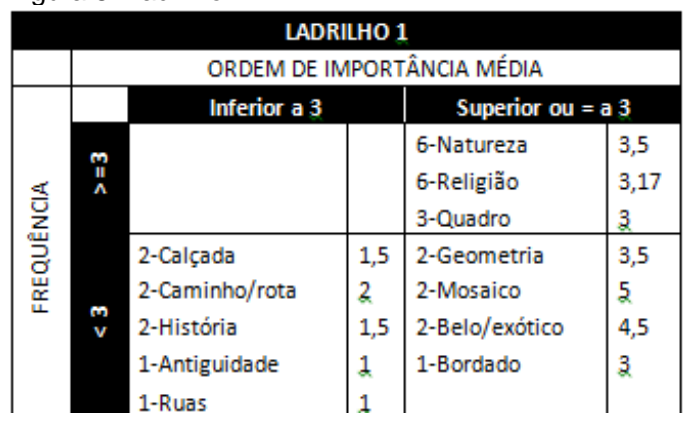

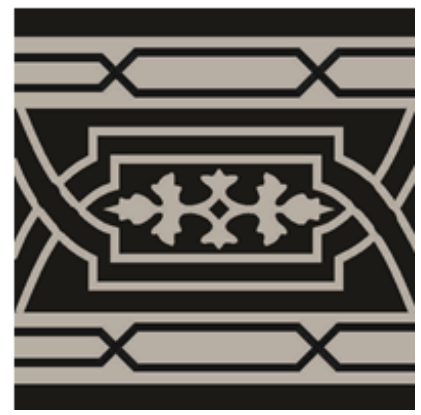

Ao reunir todas as evocações em uma análise geral do ladrilho 1, nenhum núcleo central foi estabelecido, uma vez que nenhuma das palavras muito citadas teve ordem de importância alta segundo a média. A palavra bordado continua na periferia distante após a compilação enquanto a palavra quadro, dessa vez com mais evocações, localiza-se na primeira periferia. Os itens natureza e religião, segundo as justificativas do questionário, foram muito associados à mancha gráfica central que lembra um vegetal. Para devotos recifenses a mesma mancha semelhante a um vegetal que havia sido relacionada a natureza foi associada à religião por assemelhar-se com a flor do carmelo (ícone religioso) que é bordada na estola dos frades carmelitas. 


\section{Ladrilho 2}

Figura 9: Ladrilho 2.

\begin{tabular}{|c|c|c|c|c|c|}
\hline \multicolumn{6}{|c|}{ LADRILHO 2} \\
\hline \multirow{9}{*}{ 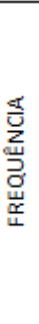 } & & \multicolumn{2}{|c|}{ Inferior a 3} & \multicolumn{2}{|c|}{ Superior ou = a 3} \\
\hline & $m$ & 3-Caminho/rota & 2 & 3-Mosaico & 4,67 \\
\hline & II & 4-Construções & 2,5 & 4-Geometria & 4,34 \\
\hline & & 3-Natureza & 2,5 & & \\
\hline & & 1-Calçada & 2 & 1-Bordado & 3 \\
\hline & & 1-Piso/Moradia & 1 & 1-Modernidade & 3 \\
\hline & $\mathrm{m}$ & 1-Medo & 2 & 2-Religião & 3 \\
\hline & & 2-Jogos & 2 & 2-Abstrato & 5 \\
\hline & & 2-Dinheiro/pressa & 2 & & \\
\hline
\end{tabular}

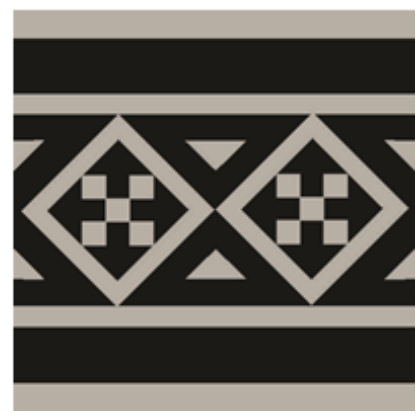

Diante da análise geral dos dados os resultados apresentam 10 evocações de palavras relacionadas a caminho/rota, construções e natureza consideradas importantes para os observadores. Fazendo um comparativo com algumas das justificativas expressas na questão 3 dos questionários, muitos disseram atribuir a ideia de caminho/rota a este ladrilho pela semelhança de seus traços com o caminho que leva ao altar da igreja, outros associam a construções como canteiros e divisórias de jardim. Os que associaram a natureza falaram sobre a semelhança dos quadrados menores com uma flor e também da composição com um jardim.

\section{Devoto recifense}

Figura 10: Devoto recifense

\begin{tabular}{|c|c|c|c|c|c|}
\hline & & DEVO & ECIFE & & \\
\hline & & ORDEM D & PORTÁ & NCIA MÉDIA & \\
\hline & & Inferior & & Superior ot & 3 \\
\hline $\mathbb{1}$ & & 5-Religião & 2,67 & 3-Geometria & 4,25 \\
\hline$\frac{\bar{v}}{2}$ & $m$ & 4-Construções & 2,5 & 5-Mosaico & 4,84 \\
\hline 岂 & $\wedge$ & 4-Natureza & 2,34 & & \\
\hline$\underset{\sim}{\ddot{\sim}}$ & & 3-Calçada & 1,75 & & \\
\hline & $m$ & 1-Antiguidade & 1 & 2-Bordado & 3 \\
\hline & & 2-Caminho/rota & 2 & 1-Quadro & 3 \\
\hline
\end{tabular}

O núcleo central deste perfil de participantes deixa bem evidente a adequação esperada de significações religiosas por parte dos devotos recifenses. Foram 5 , de 6 evocações totais, as relacionadas a religião. Esta evidência convém com a crença de que esta ferramenta é adequada para identificar memórias e representações neste artefato.

Também outras representações localizadas no núcleo central como construções, calçada e natureza podem ter sido associadas pelo repertório da cidade. Isto pode ser testado para comprovar essas evidências em pesquisa de campo com mais participantes em contexto diferentes, testando a percepção dentro e fora da igreja, nas ruas da cidade. Bordado e quadro ficam novamente no quadrante da periferia distante, demonstrando pouca representatividade.

\section{Turista brasileiro}

Anais [Oral] do 7º Congresso Internacional de Design da Informação | CIDI 2015 
Figura 11: Turista brasileiro.

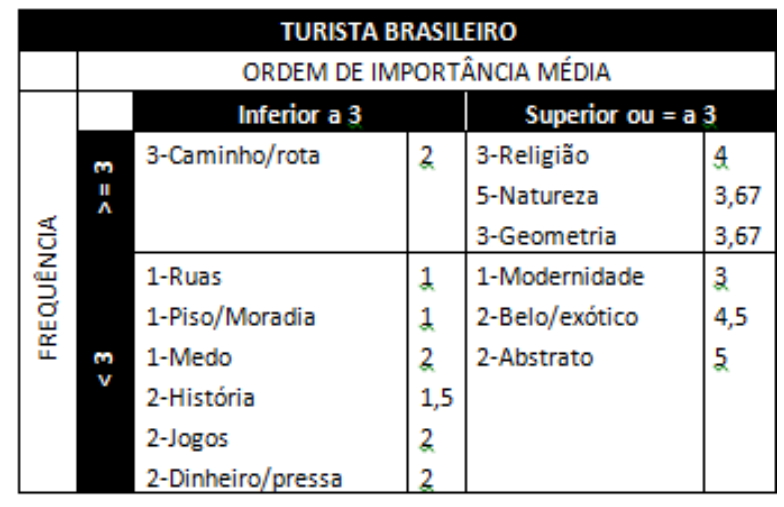

Neste perfil de participantes fica bem definido a representatividade da ideia de caminho/rota na percepção dos turistas brasileiros sobre os ladrilhos como núcleo central da representação. Conclui-se que a partir da observação das mesmas imagens indutoras do artefato os dois perfis diferentes atribuem diferentes núcleos centrais a representação de tais mensagens visuais, já que o perfil de devotos recifenses obteve por termo mais evocado a religião através das mesmas imagens indutoras e no mesmo contexto.

Acredita-se que as diferentes significações percebidas e atribuídas variam de acordo com o repertório visual, o conhecimento prévio (como cita GOODMAN em sua teoria construtivista da percepção visual) e principalmente do contexto. Essas evidências podem ser testadas e comprovadas em futuras pesquisas com este artefato em diferentes contextos e com mais participantes.

\section{Considerações finais}

Esta pesquisa de campo é um exercício para validar o uso da ferramenta da representação social de do núcleo central na pesquisa sobre os ladrilhos hidráulicos, na parte da investigação da relação do sujeito com o artefato.

Com o objetivo de identificar a relevância e contribuição do uso desta ferramenta, os problemas identificados e necessidades para um futuro experimento foram identificados os seguintes:

- A ferramenta deve ser testada em diferentes contextos para verificar a divergência na percepção das representações sociais mediante o contexto. Ex.: dentro da igreja com a observação do ladrilho em seu ambiente original e outra com abordagens fora da igreja, nas ruas da cidade;

- Em futuro experimento deve ser apresentada aos sujeitos da pesquisa a imagem do ladrilho isolado e a composição de seus módulos para a percepção completa do artefato, dentro e fora de seu contexto original;

- A realização desta pesquisa de campo com mais sujeitos possibilita maior número de evocações, consequentemente a obtenção de um núcleo central de representação social mais evocado sendo, portanto, mais representativo.

A pesquisa de campo apresentada neste ensaio atende ao objetivo inicial de procurar elementos constituintes de seu núcleo central e organizar este conteúdo, de modo que faça sentido de acordo com o contexto de seus sujeitos, a fim de reconhecer as representações 
sociais sobre os ladrilhos hidráulicos da Basílica do Carmo no Recife para turistas brasileiros e devotos recifenses a partir das diferentes memórias identificadas.

Apesar da pouca frequência de evocações devido ao número pequeno de participantes, este exercício foi importante para verificar a possibilidade de aplicação desta ferramenta na identificação de memórias e representações sociais no artefato ladrilho hidráulico. Fica então validada, a partir dos elementos encontrados, a contribuição do uso da ferramenta das teorias da representação social e núcleo central para experimento posterior com mais participantes e possíveis aperfeiçoamentos, verificando assim elementos de maior representatividade para generalizações a respeito do artefato estudado e suas representações sociais.

\section{Referências}

ABRIC, J. C. A abordagem estrutural das representações sociais. In: MOREIRA, A. S. P.; OLIVEIRA, D. C. (Org.). Estudos interdisciplinares de representação social. 2. ed. Goiânia: $A B, 2000$. p. 27-37.

DOISE, Willem. Droits de l'homme et forces des idées. Paris: PUF, 2001.

JODELET, D. Representações sociais: um domínio em expansão. In: JODELET, D. (Org.). Representações sociais. Rio de Janeiro: Eduerj, 2001. p. 17-44.

MONTEIRO, M. C. M. Passeio em Brasília Teimosa: o jogo como ferramenta para construção de identidades. UFPE. Contribuidor Orientador CAMPELLO, S. R. B. B. Monografia publicada em 29/02/2012. Disponível em: http://www.ufpe.br/ppgdesign/

MOSCOVICI, S. Das representações coletivas às representações sociais. In: JODELET, D. (Org.). Representações Sociais. Rio de Janeiro: Eduerj, 2001. p. 45-66.

REVISTA CASA E JARDIM. São Paulo, editora Globo, distribuição mensal. Disponível em:< http://revistacasaejardim.globo.com/Revista/Common/0,,GF84835-16772,00-

LADRILHO+HIDRAULICO.html\#fotogaleria=1>. Acessado em: 12 de maio de 2013

SALLES, G; VERÍSSIMO, S; BARRERO, V. Além dos tempos: Uma arte que atravessa os séculos de norte a sul do país. Revista Arquitetura e Construção, São Paulo, p. 70-75, janeiro, 2002.

\section{Sobre os autores}

Camila Brito de Vasconcelos, Mestre, UFPE, Brazil <camillacbv@hotmail.com>

Silvio Romero Botelho Barreto Campello, PhD, UFPE, Brazil <sbcampello@gmail.com>

Anais [Oral] do 7º Congresso Internacional de Design da Informação | CIDI 2015

Proceedings [Oral] of the 7th Information Design International Conference / IDIC 2015 